\title{
Fin Distance Effect at Tube-Fin Heat Exchanger
}

\author{
F. Lemfeld ${ }^{1}$, M. Muller ${ }^{1}$ K. Frana ${ }^{1}$ \\ ${ }^{1}$ Technical University of Liberec, Department of Power Engineering Equipment, Czech Republic
}

\begin{abstract}
Article deals with numerical simulation of the Tube-Fin heat exchanger. Several distances between fins are examined with intence of increasing the cooling output of the heat exchanger. Geometrical model consists of set of 2 fins with input and output area. Calculations covers the area of the gap from $2.25 \mathrm{~mm}$ to $4 \mathrm{~mm}$ with new fin geometry. For the numerical silumation was used software Ansys Fluent.
\end{abstract}

\section{Introduction}

The heat convector systems have many construction variations [1]. One of them is installation of the convector to the floor. This is the type of examined convector.

Heating convector consists of the outer container, which is the shell placed to the floor. Inside the container is the water-air exchanger with axial radiator fan. The exchanger has system of pipes equipped with the lamellae. The pipes are separated to two independent sets, one for the cooling and the other for the heating mode. Above the heat exchanger is covering aluminium grid. The example of floor heating convector is on fig. 1 .

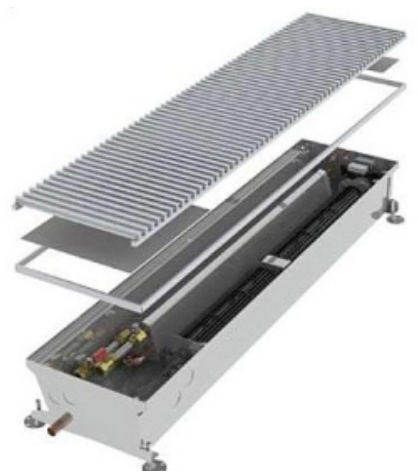

Fig. 1 - example of the floor heating convector

The temperature difference of the outer air and heating water in case of heating mode is considerably higher, then the temperature difference in the cooling mode (surrounding air to coolant). That is why the set of the pipes for the cooling has more pipes then the set of the pipes for heating (fig. 2).

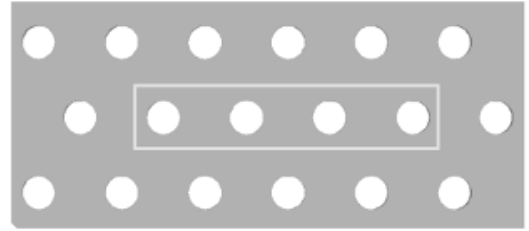

Fig. 2- lamella of the heat exchanger with marked pipes designated for heating

The cooperating company, which produces convectors of various types, had insufficient information about processes inside the convectors. That is why the numerical simulation is used to show the effects inside the convector. The objective of the work is to find possibility of optimization for the floor heating and cooling convectors.

One of the parameters which affect cooling output of the heat exchanger is fin spacing [2]. Create the heat exchanger with modified fin spacing is possible, so this parameter was examined in a range from $2.25 \mathrm{~mm}$ to 4 $\mathrm{mm}$.

Simulations were made on real models of the sinusoidal shape of the fin. Models consist of 2 fins with defined spacing, input area and output area.

Several simulations with simplified fins were carried out in previous articles [3, 4] with intention of comparison different shapes of the fins (straight, angular and sinusoidal). This article is focused to simulation on detailed models based on sinusoidal shape of the fin.

For comparison of numerical simulation results will be used data from experimental laboratory for measuring of floor heating convectors. Laboratory was created as part of research project at TU of Liberec. 


\section{Geometry and computational grid}

Model of the real fin is shown on figure 3. Entering part of model on the left side has length of $50 \mathrm{~mm}$ and output area behind a fin has $20 \mathrm{~mm}$. Model layouts correspond with the main air flow in floor heating convector. Distance between fins was examined in range from 2.25 $\mathrm{mm}$ to $4 \mathrm{~mm}$.

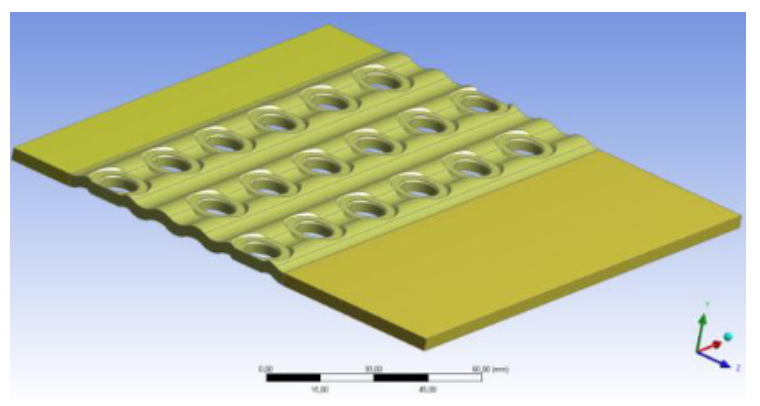

Fig. 3 - model of the sinusoidal fin

The computational grids were created in Ansys Design Modeller and has from 0.9 to about 1.2 mil cells. Models of real fins has significantly more details then theoretical lamella models in previous simulations [3] which corresponds with higher number of mesh cells. On the figure 4 is presented computational grid for model 3 $\mathrm{mm}$. Mesh inflation was created around all pipes. Mesh was generated for three independent volumes connected together.

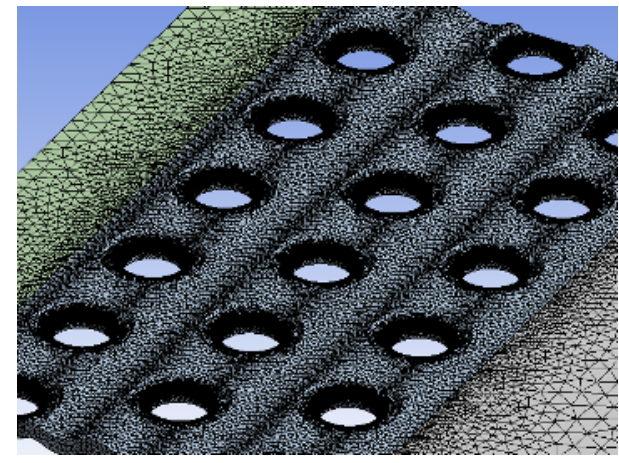

Fig. 4 - computational grid for $3 \mathrm{~mm}$ model

\section{Numerical simulation}

For numerical simulation was used commercial software Ansys Fluent. The flow is solved as an unsteady by DES turbulent model. All simulations were made in cooling mode, because heating mode of the convector works sufficiently.

Because the pipes for cooling in a real heat-exchanger covers almost whole area of the fin (see fig. 2), temperature of the fins was set to $9{ }^{\circ} \mathrm{C}$ as a constant value. Room temperature of ingoing air is $21{ }^{\circ} \mathrm{C}$. Inlet velocity is $3.65 \mathrm{~m} / \mathrm{s}$ for all models the calculations were made to the time of 1 second, and then continued for 0.6 second for time average values, all with the time step 0.001 second.
The configuration of boundary conditions is on fig. 5 . Straight entering and outgoing area has heat flux $=0$ and has no effect to the temperature of ingoing air [5].

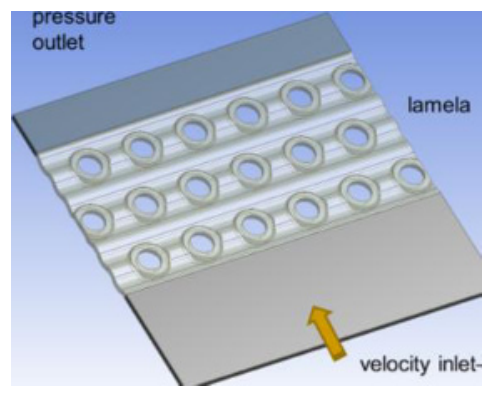

Fig. 5 - configuration of boundary conditions

For the purpose of the results comparison were measured values of the average temperature and static pressure on several planes along the fins (fig. 6). Blue plane represents velocity inlet, red pressure outlet boundary condition. In the centre are two planes at the input and output of the lamella's gap.

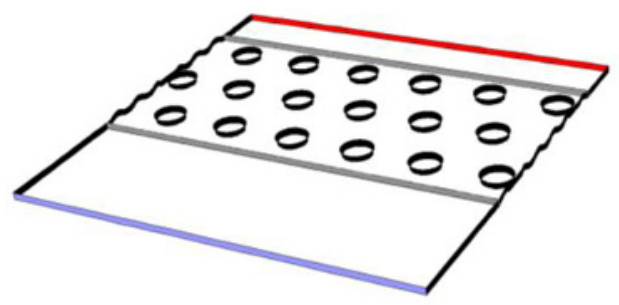

Fig. 6 - monitored planes along model

\section{Results}

First part of results shows temperature fields along fins in case of $2.5 \mathrm{~mm}$ gap (figure 7). Presented results are time averaged values.

Air enters the model from right side with temperature 294 K. Entering area has zero heat flux and don't affect air temperature. At the beginning of lamella gap air starts decreasing temperature to minimal values around $282 \mathrm{~K}$ which we can observe in several areas behind rear line of pipes. Temperature field differs across the lamellas, which is shown in 3 different model's planes.

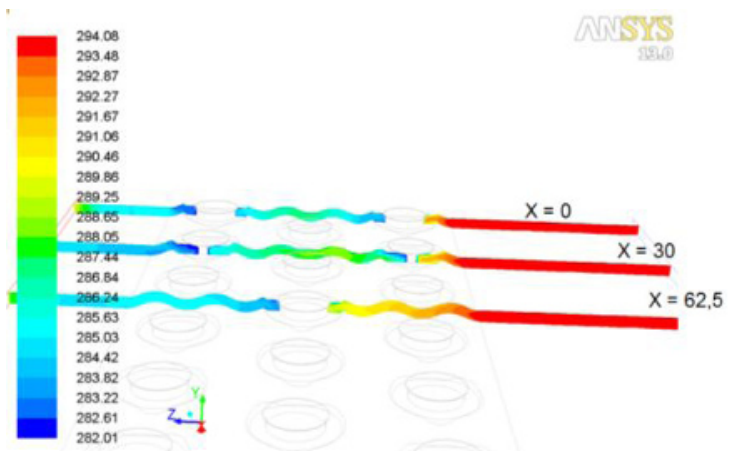

Fig. 7 - temperature field along fins in planes 
On the figure 8 are presented contours of time averaged velocity along $2.5 \mathrm{~mm}$ model. Input velocity is $3.65 \mathrm{~m} / \mathrm{s}$. Side boundaries of model are defined as wall and all air pass through area between lamellas.

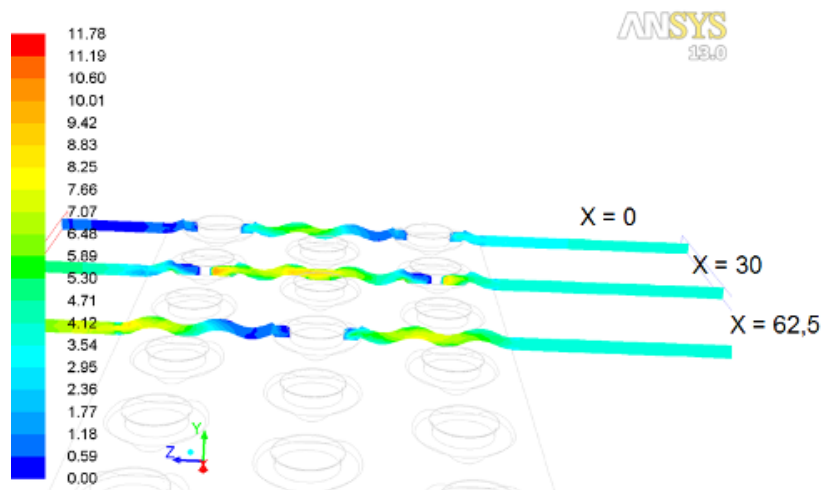

Fig. 8 - velocity field along fins in planes

On the figure 9 are presented contours of time averaged static temperature. Input temperature is $21{ }^{\circ} \mathrm{C}$ and is represented by red colour. Temperature decreases along fin. The highest temperature reduction takes place in area of first two rows of pipes from velocity input plane.
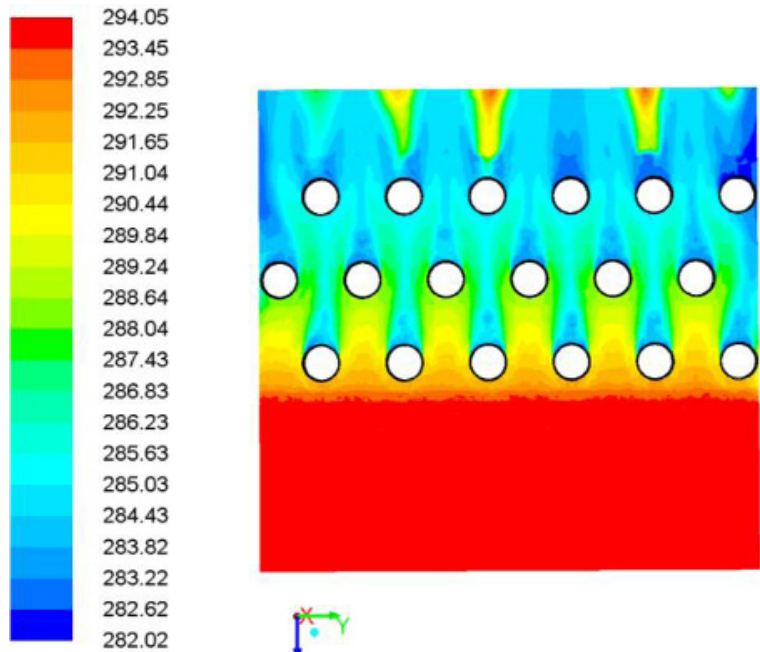

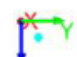

Fig. 9 - temperature field for $2.25 \mathrm{~mm}$ gap

On figure 10 are shown contours of time averaged temperature for lamella's gap $4 \mathrm{~mm}$. In comparison with $2.25 \mathrm{~mm}$ gap on figure 9 we can call temperature decreasing in this case moderate. Areas close to the pressure output with higher temperature are caused by suction behind tubes (pressure output has same temperature as input $-21^{\circ} \mathrm{C}$ ).

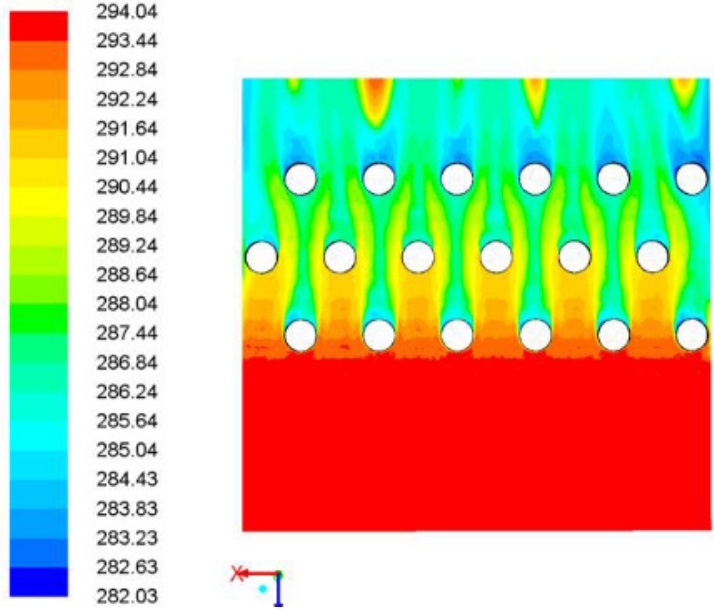

Fig. 10 - temperature field for $4 \mathrm{~mm}$ gap

On figure 11 are shown contours of time averaged static pressure for $2.25 \mathrm{~mm}$. Pressure at the input area is around $80 \mathrm{~Pa}$. Maximal value of $98 \mathrm{~Pa}$ in area of first pipe from the right is caused by model geometry and insufficient space for air flow at that area. At the output of the lamella appears under pressure values, which causes suction of air from the pressure output boundary condition represented by areas of higher temperature at the end of model (fig. 9).
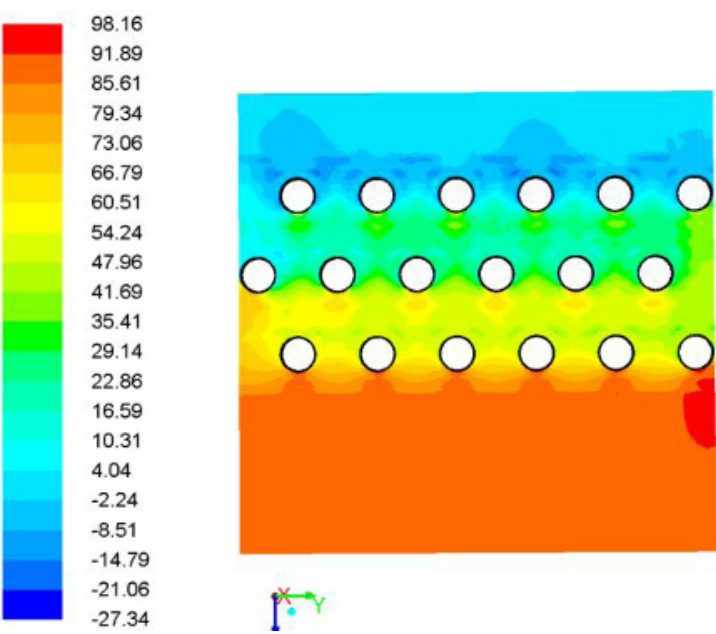

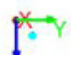

Fig. 11 - static pressure for $2.25 \mathrm{~mm}$ gap

On figure 12 are presented contours of static pressure for model of $4 \mathrm{~mm}$ gap. In comparison with $2.25 \mathrm{~mm}$ gap on figure 11 we can see lower pressure value at the area in front of heat exchanger. Highest value is also in area of first pipe from the right. Under pressure values at the output area appears with less intensity. 

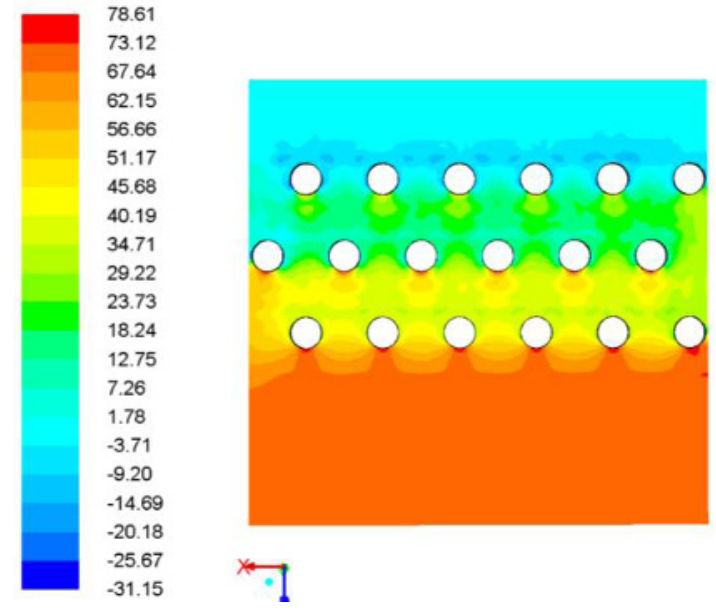

Fig. 12 - static pressure for 4 mm gap

On table 1 are presented values of theoretical normalized output for all lamellas. Temperatures are measured at the input and output of the lamella (planes are shown at fig. 6). Mass flow rises with gap expansion because of constant velocity. Theoretical output per 1 lamella gap rises with gap expansion, but if we measure normalized output per $1 \mathrm{~m}$, the best results are obtained by $2.25 \mathrm{~mm}$ gap.

Table 1. Normalized output

\begin{tabular}{|l|c|c|c|c|}
\hline lamella & $\mathbf{T}_{\text {in }}(\mathbf{K})$ & $\mathbf{T}_{\text {out }}(\mathbf{K})$ & $\mathbf{m}(\mathbf{k g} / \mathbf{s})$ & $\begin{array}{c}\text { normalized } \\
\text { output } \\
\mathbf{( W / m} / \mathbf{m})\end{array}$ \\
\hline 2.25 & 294.0 & 284.4 & $1.6 \mathrm{E}-03$ & 6421 \\
\hline 2.5 & 293.9 & 284.8 & $1.8 \mathrm{E}-03$ & 6135 \\
\hline 2.75 & 293.9 & 285.1 & $2.0 \mathrm{E}-03$ & 5932 \\
\hline 3 & 294.1 & 285.3 & $2.1 \mathrm{E}-03$ & 5856 \\
\hline 3.5 & 294.0 & 285.8 & $2.5 \mathrm{E}-03$ & 5477 \\
\hline 4 & 294.0 & 285.5 & $2.8 \mathrm{E}-03$ & 5719 \\
\hline
\end{tabular}

Table 2 present values of time averaged static pressure on different planes of the model. Value of static pressure at the input of lamella gap rises with reduction of lamella's gap. Pressure at the model output has approximately same value for all models.

Table 2. Pressure drop

\begin{tabular}{|r|c|c|c|}
\hline lamella & $\begin{array}{c}\text { lamella } \\
\text { input (Pa) }\end{array}$ & $\begin{array}{c}\text { pressure } \\
\text { output (Pa) }\end{array}$ & delta $\mathrm{p} \mathrm{(Pa)}$ \\
\hline 2.25 & 89.5 & -0.16 & 89.66 \\
\hline 2.5 & 85.8 & -0.23 & 86.05 \\
\hline 2.75 & 83.9 & -0.26 & 84.15 \\
\hline 3 & 80.1 & -0.19 & 80.28 \\
\hline 3.5 & 72.4 & -0.16 & 72.60 \\
\hline 4 & 69.4 & -0.17 & 69.59 \\
\hline
\end{tabular}

\section{Conclusions}

Several models of heat exchanger lamellas were examined with intention of finding optimal distance for heat exchanger fins. With reduction of space between lamellas rises normalized cooling output, but also raises head loss of the heat exchanger. The best cooling output was achieved by gap $2.25 \mathrm{~mm}$. For estimating of ideal set up will be performed additional simulation. Results will be compared to the experimental data.

\section{Acknowledgements}

This work was financially supported by the Particular Research Student Grant SGS 2823 at Technical University of Liberec and from the project of Technology Agency of the Czech Republic 01020231.

\section{References}

1. T. Kuppan, Heat Exchangers Design Handbook, (2000)

2. F. P. Incropera, Introduction to Heat Transfer, 5th edition, John Wiley \& Sons, (2007)

3. F. Lemfeld, K. Frana, WASET, vol. 64, (2011)

4. F. Lemfeld, 30th conference of Departments of Fluid Mechanics and Thermodynamics (2011)

5. M. BOJKO: Návody do cvičení Modelování Proudění - FLUENT, VŠB - TUO, (2008) 